\title{
Prescription Patterns of Sorafenib and Outcomes of Patients with Advanced Hepatocellular Carcinoma: A National Population Study
}

\author{
LI-CHUN LU ${ }^{1,4,7}$, PEI-JER CHEN ${ }^{2,5,6}$, YI-CHUN YEH ${ }^{3}$, CHIH-HUNG HSU ${ }^{1,4}$, \\ HO-MIN CHEN ${ }^{4}$, MEI-SHU LAI ${ }^{3}$, YU-YUN SHAO ${ }^{1,4,7}$ and ANN-LII CHENG ${ }^{1,4,5,7}$ \\ ${ }^{1}$ Graduate Institutes of Oncology and ${ }^{2}$ Clinical Medicine, College of Medicine, and \\ ${ }^{3}$ Institute of Epidemiology and Preventive Medicine, College of Public Health, \\ National Taiwan University, Taipei, Taiwan, R.O.C.; \\ ${ }^{4}$ Departments of Oncology, ${ }^{5}$ Internal Medicine and ${ }^{6}$ Hepatitis Research Center, \\ National Taiwan University Hospital, Taipei, Taiwan, R.O.C.; \\ ${ }^{7}$ National Taiwan University Cancer Center, Taipei, Taiwan, R.O.C.
}

\begin{abstract}
Background: Sorafenib is the current standard treatment for advanced hepatocellular carcinoma (HCC). We analyzed national prescription patterns and treatment outcomes of patients who received sorafenib for advanced HCC. Patients and Methods: We established a nation-wide cohort of patients who started receiving treatment with sorafenib for advanced HCC between August 2012 and July 2013 from the National Health Insurance Research Database of Taiwan and also retrieved demographic and prescription data. The databases of National Death Registry and Taiwan Cancer Registry were used for survival outcomes and cancer diagnosis information, respectively. Results: A total of 3,293 patients were enrolled. The median overall survival (OS) and time to treatment discontinuation (TTD) of all patients were 6.8 and 2.6 months, respectively. Upon the first prescription of sorafenib, $58.4 \%$ of patients received the standard dose (800 mg/day). Among them, 61.9\% had subsequent dose reduction. A total of $41.6 \%$ of patients initially received lower than standard doses; $36.1 \%$ of them had subsequent dose escalation to $800 \mathrm{mg} /$ day. Being male (odds ratio=1.41; $p<0.001$ ) and treatment year of 2012 (odds ratio=1.28, $p=0.002)$ were associated with the standard initial dose. Patients who received standard initial dose of sorafenib,
\end{abstract}

Correspondence to: Yu-Yun Shao, MD, Graduate Institute of Oncology, College of Medicine, National Taiwan University; Department of Oncology, National Taiwan University Hospital, 7 Chung-Shan South Road, Taipei 10002, Taiwan. Tel: +886 223123456 ext. 66008, Fax: +886 223711174, e-mail: yuyunshao@gmail.com

Key Words: Database research, dose, hepatocellular carcinoma, population study, prognosis, sorafenib. compared to patients who received lower initial doses, exhibited longer OS (median of $7.8 \mathrm{vs.} 6.6$ months, $p<0.001$ ) but similar TTD (median of 2.6 vs. 2.9 months, $p=0.840$ ). Conclusion: A considerable number of patients with advanced HCC received less than the standard dose of sorafenib. The treatment outcomes in the general population were consistent with those reported in clinical trials.

Hepatocellular carcinoma (HCC) is the sixth most common malignancy and the third leading cause of cancer-related deaths globally (1). For patients with advanced HCC, sorafenib, a multikinase inhibitor mainly targeting rapid accelerated fibrosarcoma (RAF) and vascular endothelial growth factor receptors (2), was proven to provide survival benefits with modest efficacy $(3,4)$. In a phase III trial conducted in the Asia-Pacific region, the median overall survival (OS) and time to progression were only 6.5 and 2.8 months, respectively (4). However, many other novel agents have not proven as effective in large clinical trials (5-8). Although immune checkpoint inhibitors showed potential as treatment for advanced HCC and regorafenib was demonstrated to prolong survival after failure of sorafenib treatment (9-11), sorafenib remains the only standard firstline treatment for advanced HCC.

The standard starting dose of sorafenib is $800 \mathrm{mg} /$ day. However, in pivotal phase III trials of sorafenib in advanced HCC, $80 \%$ of patients experienced adverse events such as diarrhea, hand-foot skin reaction, and fatigue. Approximately $30 \%$ and $44 \%$ of patients required dose reduction and treatment interruption, respectively $(3,4)$. Therefore, in real-world clinical practice, as reported by regional cohort studies, a substantial number of patients received lower initial doses of sorafenib $(12,13)$. In the 
Global Investigation of Therapeutic Decisions in HCC and of its Treatment with Sorafenib (GIDEON) study, a multinational observational registry study that evaluated the safety and efficacy of sorafenib in clinical practice, significant differences regarding initial doses of sorafenib were observed and nearly half of the patients had sorafenib dose modification during the treatment course (14).

Although the GIDEON study enrolled 3,202 patients in 39 countries, it had an inherent selection bias because it depended on patient enrollment from investigators (14). In Taiwan, the National Health Insurance (NHI) program, a single-payer mandatory insurance system, covers more than $99 \%$ of the Taiwanese population (15). NHI started issuing reimbursements for sorafenib to patients with advanced HCC on August 1, 2012. We, thus, performed this study to evaluate the prescription patterns and treatment outcomes of sorafenib in an unselected nationwide population.

\section{Patients and Methods}

Data source. We established a nationwide cohort study by identifying sorafenib prescription from the NHI research database (NHIRD) and diagnosis of HCC from the Taiwan Cancer Registry database. All major cancer care providers in Taiwan with more than 50 beds are obligated to submit data to the Taiwan Cancer Registry database, which covered $98.4 \%$ of new cancer cases by 2012 (16). We also employed the National Death Registry database to determine death events. In order to comply with personal electronic data privacy regulations, personal identities were encrypted, and all data were analyzed anonymously. This study was approved by the Institute Research Ethical Committee of the National Taiwan University Hospital (201511069RINC).

Study population and sorafenib treatment. We reviewed the database of the NHIRD to find patients who were prescribed sorafenib for the first time between August 2012, and July 2013. We linked the data of these patients by their identification numbers to those in the Taiwan Cancer Registry database for patients who were newly diagnosed with HCC from 1979 to 2013. Costs for sorafenib have been fully reimbursed without co-payment by NHI since August 1 2012 for patients who had HCC not amenable to locoregional therapy and macroscopic vascular invasion or extrahepatic spread (patients were also required to have Child-Pugh A liver reserve). Physicians need to apply for the use of sorafenib and provide clinical data meeting the aforementioned requirements. The application has to be renewed every 2 months with dynamic imaging evidence showing no disease progression under sorafenib treatment.

Study variables and end-points. Patient demographic data were retrieved from the Taiwan Cancer Registry database. Sorafenib prescription data and information regarding other HCC treatments were obtained from the NHIRD. OS was calculated from the first prescription date of sorafenib to death. Time to treatment discontinuation (TTD) was measured from the first prescription date of sorafenib to the last prescription date of sorafenib or death. Data were censored if events did not occur before the last follow-up date, December 31, 2013.
Table I. Baseline patient characteristics.

\begin{tabular}{|c|c|}
\hline Variable & $\mathrm{N}(\%)$ \\
\hline All & $3293(100)$ \\
\hline \multicolumn{2}{|l|}{ Gender } \\
\hline Male & $2585(78.5)$ \\
\hline Female & $708(21.5)$ \\
\hline \multicolumn{2}{|l|}{ Age } \\
\hline Median (range) & $60(18-85)$ \\
\hline 18-64 Years & $2058(62.5)$ \\
\hline$\geq 65$ Years & $1235(37.5)$ \\
\hline \multicolumn{2}{|l|}{ Treatment year } \\
\hline 2012 & $1714(52.0)$ \\
\hline 2013 & $1579(48.0)$ \\
\hline \multicolumn{2}{|l|}{ Hospital level } \\
\hline Medical center & $2026(61.5)$ \\
\hline Others & $1267(38.5)$ \\
\hline \multicolumn{2}{|l|}{ Hospital area } \\
\hline Taipei & $962(29.2)$ \\
\hline Northern & $300(9.1)$ \\
\hline Central & $738(22.4)$ \\
\hline Southern & $729(22.1)$ \\
\hline Kaoping & $504(15.3)$ \\
\hline Eastern & $60(1.8)$ \\
\hline \multicolumn{2}{|l|}{ Physician specialty } \\
\hline Gastroenterology and hepatology & $1520(46.2)$ \\
\hline Hemato-oncology & 976 (29.6) \\
\hline Surgery & $530(16.1)$ \\
\hline Others & $267(8.1)$ \\
\hline \multicolumn{2}{|c|}{ Time from initial HCC diagnosis to receive sorafenib } \\
\hline$<3$ Months & $442(13.4)$ \\
\hline$\geq 3-6$ Months & $424(12.9)$ \\
\hline$\geq 6-12$ Months & $527(16.0)$ \\
\hline$\geq 1-2$ Years & $594(18.0)$ \\
\hline$\geq 2-4$ Years & $610(18.5)$ \\
\hline$\geq 4$ Years & $696(21.1)$ \\
\hline \multicolumn{2}{|l|}{ Prior locoregional therapy } \\
\hline Any & $2323(70.5)$ \\
\hline Hepatectomy & $939(28.5)$ \\
\hline Local ablation & $778(23.6)$ \\
\hline Transarterial chemoembolization & $1958(59.5)$ \\
\hline
\end{tabular}

Statistical methods. Statistical analyses were performed using SAS statistical software (version 9.4; SAS Institute, Cary, NC, USA). The associations between categorical variables and initial dose of sorafenib were analyzed using the chi-square test. A multivariate analysis of the potential factors influencing the initial sorafenib dose was performed using the logistic regression model with a random effect for hospitals to account for patient clustering within a hospital. OS and TTD of patients based on distinct variables were estimated using the Kaplan-Meier method and compared using the log-rank test. The Cox proportional hazards model was used in the multivariate analysis to examine the effect of different variables on OS and TTD. Two-sided $p$-values of 0.05 or less was considered statistically significant. 
Table II. Initial doses of sorafenib and subsequent dose adjustment.

\begin{tabular}{|c|c|c|}
\hline \multirow[t]{2}{*}{ Variable } & \multicolumn{2}{|c|}{$\mathrm{N}(\%)$} \\
\hline & Initial standard dose & Other initial dose \\
\hline All & $1838(100.0)$ & $1309(100.0)$ \\
\hline \multicolumn{3}{|c|}{ Initial dose (mg/day) } \\
\hline 200 & 0 & $170(13.0)$ \\
\hline 400 & 0 & $1003(76.6)$ \\
\hline 600 & 0 & $136(10.4)$ \\
\hline 800 & $1838(100.0)$ & 0 \\
\hline \multicolumn{3}{|c|}{ Dose modification ${ }^{a}$} \\
\hline Yes & $1138(61.9)$ & $604(46.1)$ \\
\hline No & $700(38.1)$ & $705(53.9)$ \\
\hline \multicolumn{3}{|c|}{ Subsequent standard dose $\mathrm{b}^{\mathrm{b}}$} \\
\hline Yes & NA & $472(36.1)$ \\
\hline \multicolumn{3}{|c|}{ Mean dose (mg/day) } \\
\hline Mean (SD) & $675.3(341.8)$ & $473.5(228.7)$ \\
\hline
\end{tabular}

NA: Not applicable; SD: standard deviation. aDose increase or reduction. ${ }^{b}$ Standard dose $(800 \mathrm{mg} /$ day $)$ prescribed any time after initial administration.

\section{Results}

Patient demographics. A total of 3293 patients were included in the study; $78.5 \%$ of them were male, and $37.5 \%$ aged $\geq 65$ years (Table I). More than half of the patients $(61.5 \%)$ were treated at medical centers. Sorafenib was mostly prescribed by physicians specialized in gastroenterology and hepatology (46.2\%), hemato-oncolgy $(29.6 \%)$, and surgery $(16.1 \%)$. In terms of the time between initial diagnosis of HCC to first receipt of sorafenib, $13.4 \%$ of patients had sorafenib treatment within 3 months of HCC diagnosis. The majority $(70.5 \%)$ of patients had received prior locoregional therapies, including surgery (28.5\%), local ablation (23.6\%), and transarterial chemoembolization (TACE; 59.5\%) before receiving sorafenib treatment (Table I). Among patients who received TACE before sorafenib treatment, the median number of prior TACE was 2 (range $=1-27$ ).

Prescription patterns of sorafenib. Overall, 146 out of 3,293 patients had missing data on detailed sorafenib prescription, consequently only 3147 patients were analyzed. A total of $1838(58.4 \%)$ patients received the standard initial dose of sorafenib ( $800 \mathrm{mg} / \mathrm{day})$, and $1138(61.9 \%)$ of them required subsequent dose reduction (Table II). The most common $(80.7 \%)$ lowest prescribed dose after dose reduction was 400 $\mathrm{mg} /$ day; the lowest dose was $600 \mathrm{mg} /$ day and $200 \mathrm{mg} /$ day in $9.6 \%$ and $9.8 \%$ of patients, respectively. A total of 1,309 $(41.6 \%)$ patients received lower initial doses, with $400 \mathrm{mg}$ /day being the most common reduced initial dose (76.6\%). Among patients treated with lower initial doses, $36.1 \%$ experienced dose escalation to $800 \mathrm{mg} /$ day during the
Table III. Factors associated with initial standard dose of sorafenib.

\begin{tabular}{|c|c|c|c|}
\hline Variable & Adjusted OR & $95 \% \mathrm{CI}$ & $p$-Value \\
\hline Age: $\geq 65 v s .<65$ years & 0.86 & $0.73-1.01$ & 0.073 \\
\hline Gender: Male $v s$. female & 1.41 & $1.16-1.70$ & $<0.001$ \\
\hline Treatment year: 2012 vs. 2013 & 1.28 & $1.10-1.51$ & 0.002 \\
\hline $\begin{array}{l}\text { Time from initial HCC diagnosis } \\
\text { to sorafenib treatment }\end{array}$ & & & 0.077 \\
\hline$<3$ Months & Reference & & \\
\hline$\geq 3-6$ Months & 1.00 & $0.75-1.34$ & \\
\hline$\geq 6-12$ Months & 1.23 & $0.93-1.62$ & \\
\hline$\geq 1-2$ Years & 1.42 & $1.08-1.88$ & \\
\hline$\geq 2-4$ Years & 1.30 & $0.99-1.71$ & \\
\hline$\geq 4$ Years & 1.26 & $0.96-1.65$ & \\
\hline $\begin{array}{l}\text { Hospital level: Medical } \\
\text { center } v s \text {. other }\end{array}$ & 1.13 & $0.64-2.01$ & 0.667 \\
\hline Hospital area & & & 0.191 \\
\hline Taipei & Reference & & \\
\hline Northern & 0.58 & $0.19-1.83$ & \\
\hline Central & 1.52 & $0.72-3.17$ & \\
\hline Southern & 1.02 & $0.48-2.19$ & \\
\hline Kaoping & 2.46 & $1.06-5.75$ & \\
\hline Eastern & 1.46 & $0.37-5.78$ & \\
\hline Physician specialty & & & 0.070 \\
\hline Hemato-oncology & Reference & & \\
\hline Surgery & 1.13 & $0.87-1.48$ & \\
\hline Gastroenterology & 1.06 & $0.86-1.32$ & \\
\hline Other internal medicine & 0.50 & $0.28-0.91$ & \\
\hline Other & 1.36 & $0.89-2.10$ & \\
\hline
\end{tabular}

OR: Odds ratio; CI: confidence interval.

treatment. The mean dose of all patients was $594.1 \mathrm{mg} /$ day. The mean doses of patients with standard initial dose and lower initial doses were $675.3 \mathrm{mg} /$ day and $473.5 \mathrm{mg} /$ day, respectively (Table II).

In multivariate analysis, being male [vs. being female, odds ratio $(\mathrm{OR})=1.41 ; p<0.001)$ and starting sorafenib treatment in 2012 ( $v s .2013, \mathrm{OR}=1.28 ; p=0.002$ ) were factors independently associated with being prescribed the standard initial dose of sorafenib (Table III). Old age ( $\geq 65$ years) was associated with a trend for lower initial doses $(\mathrm{OR}=0.86 ; p=0.073)$. The initial dose of sorafenib was not associated with the time from $\mathrm{HCC}$ diagnosis to receipt of sorafenib, hospital type, hospital area, nor physician specialty (Table III).

Survival analysis. As of December 31, 2013, 2,189 patients $(66.5 \%)$ had died and 2863 patients (86.9\%) had discontinued sorafenib treatment. The mean follow-up time was 6.9 months. The median OS and median TTD of the entire cohort were 6.8 [95\% confidence interval $(\mathrm{CI})=6.5$ 7.2) and $2.6(95 \% \mathrm{CI}=2.5-2.8)$ months, respectively (Figure 1). The 1-month survival rate and treatment discontinuation rate were $95.1 \%$ and $14.6 \%$, respectively. The 2 -month 
survival rate and treatment discontinuation rate were $87.4 \%$ and $35.5 \%$, respectively. Patients who received the standard initial dose of sorafenib, compared to patients who received lower initial doses, exhibited significantly longer OS (median $7.8 v s .6 .6$ months, $p<0.001$; Figure 2A), but similar TTD (median 2.6 vs. 2.9 months, $p=0.840$; Figure 2B). A longer time from initial HCC diagnosis to sorafenib treatment was associated with significantly longer OS $(p<0.001$; Figure 2C) and longer TTD ( $p<0.001$; Figure 2D).

In multivariate analysis adjusted for age, sex, time from initial HCC diagnosis to sorafenib treatment, treatment year, hospital level, and hospital area, being prescribed the standard initial dose of sorafenib remained an independent predictor for longer OS [hazard ratio $(\mathrm{HR})=0.83,95 \%$ $\mathrm{CI}=0.76-0.91, p<0.001)$, but not for TTD $(p=0.494)$ (Table IV). Younger age and longer time from initial HCC diagnosis to sorafenib treatment were independent predictors for longer OS and TTD (Table IV).
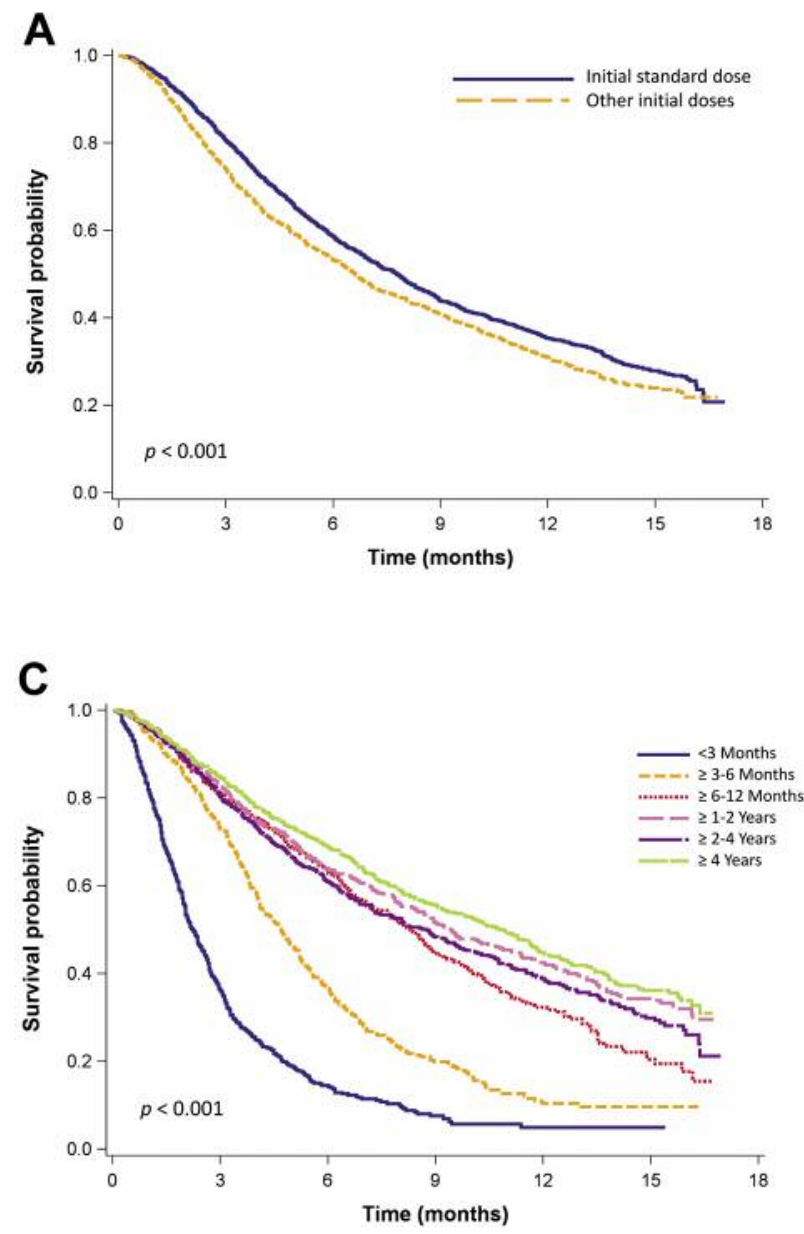

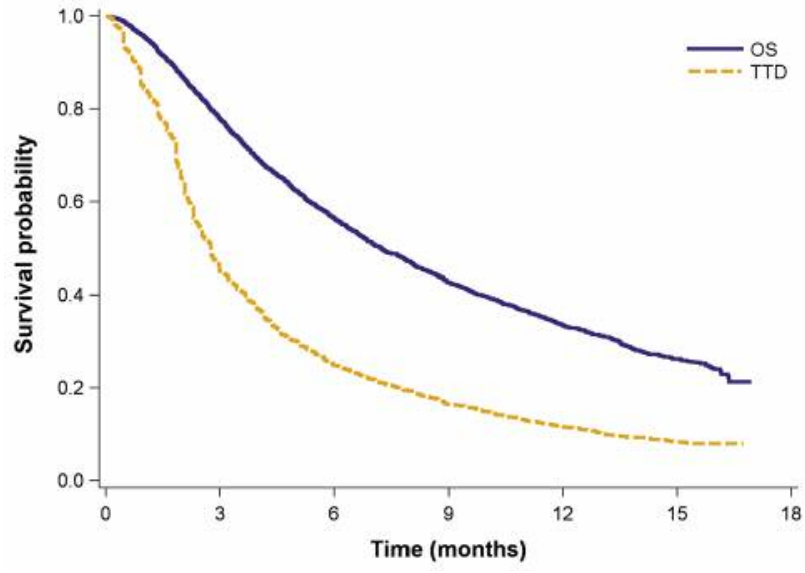

Figure 1. Kaplan-Meier plots of overall survival (OS) and time to treatment discontinuation (TTD) for all patients. p-Values were determined using the log-rank test.
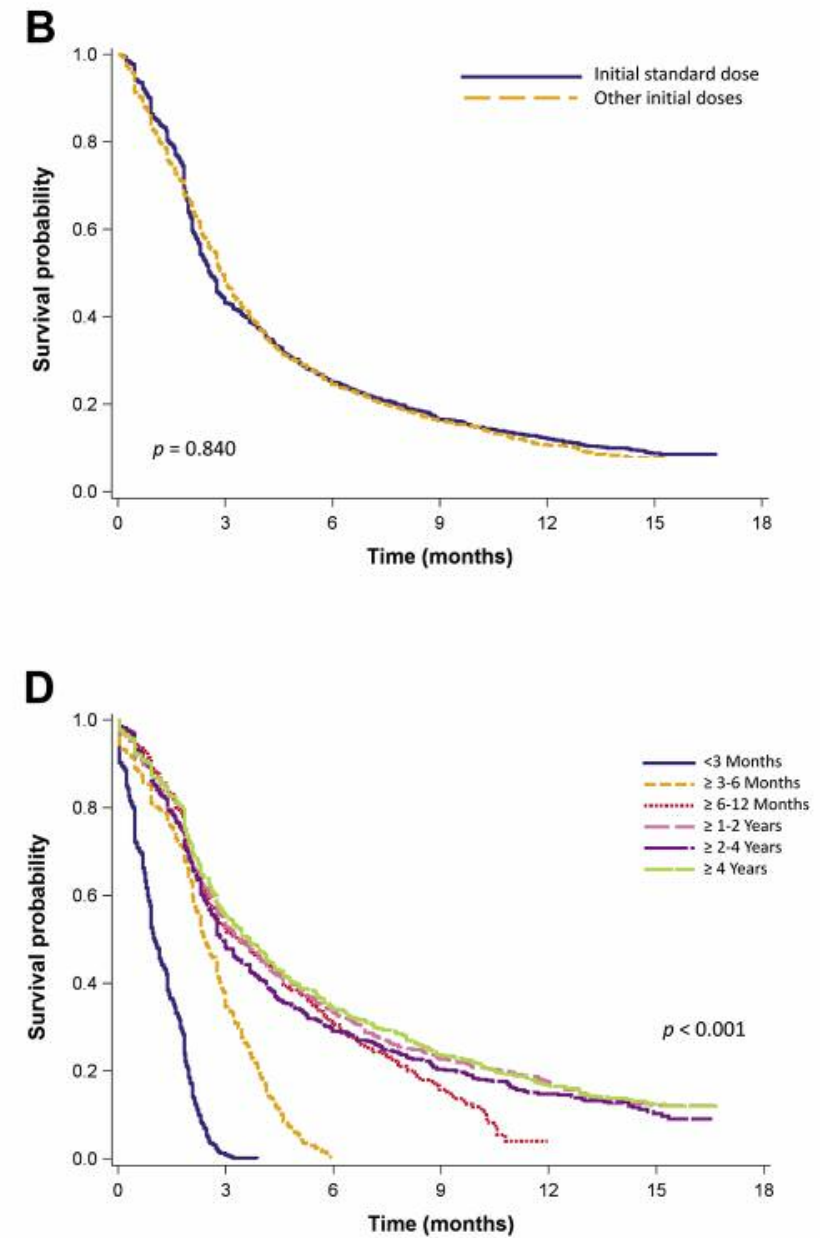

Figure 2. Kaplan-Meier plots of overall survival $(O S)(A, C)$ and time to treatment discontinuation $(T T D)(B, D)$ for subgroups of patients with different initial doses of sorafenib $(A, B)$ and different durations of time from HCC diagnosis to receipt of sorafenib $(C, D)$. 
Lu et al: Prescription Patterns of Sorafenib for HCC

Table IV. Univariate and multivariate analysis of overall survival and time to treatment discontinuation according to different variables.

\begin{tabular}{|c|c|c|c|c|c|c|c|c|c|c|c|c|}
\hline \multirow[b]{3}{*}{ Variable } & \multicolumn{6}{|c|}{ Overall survival } & \multicolumn{6}{|c|}{ Time to treatment discontinuation } \\
\hline & \multicolumn{3}{|c|}{ Univariate } & \multicolumn{3}{|c|}{ Multivariate ${ }^{\mathrm{a}}$} & \multicolumn{3}{|c|}{ Univariate } & \multicolumn{3}{|c|}{ Multivariate ${ }^{a}$} \\
\hline & HR & $95 \% \mathrm{CI}$ & $p$-Value & HR & $95 \% \mathrm{CI}$ & $p$-Value & HR & $95 \% \mathrm{CI}$ & $p$-Value & HR & $95 \% \mathrm{CI}$ & $p$-Value \\
\hline Age: $\geq 65 v s .<65$ years & 0.98 & $0.90-1.06$ & 0.582 & 1.16 & $1.05-1.27$ & 0.002 & 0.98 & $0.91-1.06$ & 0.577 & 1.19 & $1.10-1.29$ & $<0.001$ \\
\hline Sex: male $v s$. female & 0.96 & $0.87-1.06$ & 0.432 & 0.96 & $0.86-1.06$ & 0.426 & 0.96 & $0.88-1.05$ & 0.381 & 0.92 & $0.84-1.01$ & 0.081 \\
\hline Time from initial HCC diagnosis & & & $<0.001$ & & & $<0.001$ & & & $<0.001$ & & & $<0.001$ \\
\hline$<3$ Months & Ref. & & & Ref. & & & Ref. & & & Ref. & & \\
\hline$\geq 3-6$ Months & 0.48 & $0.42-0.56$ & & 0.47 & $0.40-0.55$ & & 0.37 & $0.32-0.42$ & & 0.33 & $0.28-0.38$ & \\
\hline$\geq 6-12$ Months & 0.26 & $0.23-0.30$ & & 0.26 & $0.22-0.31$ & & 0.19 & $0.17-0.22$ & & 0.18 & $0.15-0.20$ & \\
\hline$\geq 1-2$ Years & 0.21 & $0.18-0.25$ & & 0.21 & $0.18-0.25$ & & 0.17 & $0.15-0.20$ & & 0.15 & $0.13-0.18$ & \\
\hline$\geq 2-4$ Years & 0.24 & $0.21-0.27$ & & 0.24 & $0.20-0.28$ & & 0.19 & $0.16-0.21$ & & 0.17 & $0.14-0.19$ & \\
\hline$\geq 4$ Years & 0.19 & $0.17-0.22$ & & 0.19 & $0.16-0.22$ & & 0.16 & $0.14-0.19$ & & 0.14 & $0.12-0.17$ & \\
\hline $\begin{array}{l}\text { Initial dosage: } \\
\text { standard } v s . \text { others }\end{array}$ & 0.86 & $0.79-0.94$ & 0.001 & 0.83 & $0.76-0.91$ & $<0.001$ & 0.99 & $0.92-1.07$ & 0.842 & 0.97 & $0.90-1.05$ & 0.494 \\
\hline Treatment year: & & & & & & & & & & & & \\
\hline 2013 vs. 2012 & 1.18 & $1.08-1.29$ & $<0.001$ & 1.01 & $0.91-1.11$ & 0.923 & 1.06 & $0.98-1.14$ & 0.136 & 0.91 & $0.84-0.99$ & 0.020 \\
\hline $\begin{array}{l}\text { Hospital level: } \\
\text { medical center vs. other }\end{array}$ & 0.95 & $0.87-1.03$ & 0.220 & 1.04 & $0.94-1.15$ & 0.456 & 0.96 & $0.89-1.03$ & 0.274 & 1.01 & $0.92-1.10$ & 0.886 \\
\hline Hospital area & & & 0.059 & & & 0.499 & & & $<0.001$ & & & $<0.001$ \\
\hline Taipei & Ref & & & Ref & & & Ref & & & Ref & & \\
\hline Northern & 0.89 & $0.76-1.04$ & & 0.95 & $0.80-1.13$ & & 0.75 & $0.65-0.86$ & & 0.74 & $0.64-0.86$ & \\
\hline Central & 0.83 & $0.74-0.93$ & & 0.94 & $0.83-1.07$ & & 0.78 & $0.70-0.86$ & & 0.80 & $0.72-0.90$ & \\
\hline Southern & 0.92 & $0.82-1.03$ & & 0.97 & $0.85-1.10$ & & 0.85 & $0.76-0.94$ & & 0.86 & $0.77-0.96$ & \\
\hline Kaoping & 0.97 & $0.85-1.10$ & & 1.03 & $0.90-1.18$ & & 1.12 & $1.00-1.25$ & & 1.18 & $1.05-1.33$ & \\
\hline Eastern & 0.98 & $0.71-1.34$ & & 1.26 & $0.90-1.75$ & & 0.61 & $0.46-0.82$ & & 0.62 & $0.46-0.84$ & \\
\hline
\end{tabular}

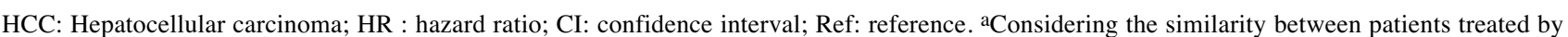
the same physician specialty, the Cox proportional hazards model was stratified by physician specialty to examine the effect of different variables on overall survival and time to treatment discontinuation.

Locoregional therapy during and after sorafenib treatment. During the sorafenib treatment period, 614 (18.6\%) patients received locoregional therapies, including TACE (16.8\%) and local ablation (2.0\%). After discontinuing sorafenib, 308 (13.2\%) patients received further locoregional therapies, including TACE (11.6) and local ablation (1.5\%).

\section{Discussion}

In the current study, the prescription patterns of sorafenib and treatment outcomes of patients with advanced HCC were demonstrated in an unselected general population by using national databases in Taiwan. To our knowledge, this is the largest cohort study in a single country to evaluate sorafenib treatment in real-world clinical practice. We found that a considerable number of patients with advanced HCC received lower than standard doses of sorafenib, either initially or during the treatment period. Treatment outcomes in terms of OS and TTD of this nationwide cohort were similar to those reported in a phase III clinical trial conducted in the Asia-Pacific region (4).
Table V. Percentage of prior locoregional therapies according to time from initial hepatocellular carcinoma diagnosis.

\begin{tabular}{lcc}
\hline $\begin{array}{l}\text { Time from initial } \\
\text { HCC diagnosis }\end{array}$ & $\mathrm{N}$ & $\begin{array}{c}\text { Prior locoregional } \\
\text { therapies } \\
\mathrm{N}(\%)\end{array}$ \\
\hline Total & 3,293 & $2323(70.5)$ \\
$<3$ Months & 442 & $64(14.5)$ \\
$\geq 3-6$ Months & 424 & $155(36.6)$ \\
$\geq 6-12$ Months & 527 & $358(67.9)$ \\
$\geq 1-2$ Years & 594 & $490(82.5)$ \\
$\geq 2-4$ Years & 610 & $577(94.6)$ \\
$\geq 4$ Years & 696 & $679(97.6)$ \\
\hline
\end{tabular}

Common side-effects of sorafenib, including diarrhea, hand-foot skin reaction, and fatigue, may lead to dose reduction or treatment interruption. Our results demonstrate that in real-world practice, some Taiwanese physicians preferred prescribing sorafenib with a lower initial dose and 
then escalating the dose according to the tolerance of patients. It is conceivable that male and younger patients may tolerate the adverse effects of sorafenib better and therefore were more likely to receive the standard initial dose. Our study also showed that patients in 2013 were more likely to be prescribed lower initial doses compared with those in 2012, implying that some physicians shifted to employing a 'ramp-up' strategy after their previous experiences.

Initial doses of sorafenib varied substantially between countries. In the GIDEON study, nearly all Chinese patients received the standard $800 \mathrm{mg} /$ day dose of sorafenib initially (17). However, in Korea and Japan, only $67.0 \%$ and $45.5 \%$ of patients, respectively, started with the standard dose (14, 18); more than $80 \%$ of patients in Europe and Latin America received the standard initial dose of sorafenib, but only about half of American patients received the standard dose initially (14). Although patients in the GIDEON study were diverse in their disease stage and liver reserve, these data suggested that the cause of different initial doses among countries might be attributable to practice patterns or reimbursement policies (19).

Prior studies reported that starting with a lower sorafenib dose might lead to similar outcomes and higher patient compliance in patients with advanced $\operatorname{HCC}(12,13,20)$. We found that patients who received the standard initial dose of sorafenib exhibited longer OS than those who received lower initial doses. However, the TTD was similar for patients treated with standard and those treated with lower than standard doses. These results failed to imply that the full initial dose actually lead to better sorafenib efficacy. Instead, some unobtainable factors that were associated with both the initial sorafenib dose and prognosis, such as performance status and comorbidities of patients, may be the actual cause of OS differences in our study (21-24).

Patients with longer time from initial HCC diagnosis to sorafenib treatment exhibited longer OS and TTD. These patients were probably diagnosed with HCC at early or intermediate stages, and they were more likely to receive prior locoregional therapies (Table V). Although the underlying mechanism of distinct prognosis between patients with recurrent HCC and patients with initially advanced HCC warrants further investigation, we suggest stratifying this factor while designing future clinical trials in advanced HCC.

There were several limitations in this retrospective study. Although HCC etiology may be associated with the treatment efficacy of sorafenib (25), we did not have such information. More relevant, whether the patients received antiviral therapies is not known. Data regarding adverse events and tumor responses were also unavailable from the databases. Accordingly, the reasons for discontinuation of sorafenib could not be assessed. However, $35.5 \%$ of patients discontinued sorafenib before completing 2 months of treatment, and presumably many of them were intolerant to toxicities of sorafenib. Additionally, the actual time to disease progression was unknown, and we were therefore only able to use TTD as a surrogate. However, since using an unselected patient cohort, the study still offers unbiased observation of patients who received sorafenib for advanced HCC.

In summary, we demonstrated that a considerable number of patients with advanced $\mathrm{HCC}$ received lower than standard doses of sorafenib in real-world clinical practice. The treatment outcomes of patients who received sorafenib for advanced HCC in the general population were consistent with those reported in clinical trials.

\section{Conflicts of Interest}

The Authors have no conflicts of interest to declare.

\section{Acknowledgements}

This study was supported by grants from the Ministry of Science and Technology, Taiwan (MOST 102-2314-B-002-120, MOST-1032314-B-002-181-MY2, MOST-103-2314-B-002-090, MOST-1032314-B-002-092, MOST 104-2314-B-002-073) and the National Taiwan University Hospital (NTUH 103-S2314, NTUH 105S2954, NTUH 106-S3596).

\section{References}

1 International Agency for Cancer Research. GLOBOCAN 2008. Available from: http://globocan.iarc.fr/. Accessed August 20, 2016.

2 Wilhelm SM, Carter C, Tang L, Wilkie D, McNabola A, Rong $\mathrm{H}$, Chen C, Zhang X, Vincent P, McHugh M, Cao Y, Shujath J, Gawlak S, Eveleigh D, Rowley B, Liu L, Adnane L, Lynch M, Auclair D, Taylor I, Gedrich R, Voznesensky A, Riedl B, Post LE, Bollag G and Trail PA: BAY 43-9006 exhibits broadspectrum oral antitumor activity and targets the RAF/MEK/ERK pathway and receptor tyrosine kinases involved in tumor progression and angiogenesis. Cancer Res 64: 7099-7109, 2004.

3 Llovet JM, Ricci S, Mazzaferro V, Hilgard P, Gane E, Blanc JF, de Oliveira AC, Santoro A, Raoul JL, Forner A, Schwartz M, Porta C, Zeuzem S, Bolondi L, Greten TF, Galle PR, Seitz JF, Borbath I, Haussinger D, Giannaris T, Shan M, Moscovici M, Voliotis D and Bruix J: Sorafenib in advanced hepatocellular carcinoma. N Engl J Med 359: 378-390, 2008.

4 Cheng AL, Kang YK, Chen Z, Tsao CJ, Qin S, Kim JS, Luo R, Feng J, Ye S, Yang TS, Xu J, Sun Y, Liang H, Liu J, Wang J, Tak WY, Pan H, Burock K, Zou J, Voliotis D and Guan Z: Efficacy and safety of sorafenib in patients in the Asia-Pacific region with advanced hepatocellular carcinoma: a phase III randomised, double-blind, placebo-controlled trial. Lancet Oncol 10: 25-34, 2009.

5 Cheng AL, Kang YK, Lin DY, Park JW, Kudo M, Qin S, Chung HC, Song X, Xu J, Poggi G, Omata M, Pitman Lowenthal S, Lanzalone S, Yang L, Lechuga MJ and Raymond E: Sunitinib versus sorafenib in advanced hepatocellular cancer: results of a randomized phase III trial. J Clin Oncol 31: 4067-4075, 2013. 
6 Johnson PJ, Qin S, Park JW, Poon RT, Raoul JL, Philip PA, Hsu $\mathrm{CH}, \mathrm{Hu} \mathrm{TH}, \mathrm{Heo} \mathrm{J}, \mathrm{Xu} \mathrm{J}$, Lu L, Chao Y, Boucher E, Han KH, Paik SW, Robles-Avina J and Kudo M, Yan L, Sobhonslidsuk A, Komov D, Decaens T, Tak WY, Jeng LB, Liu D, Ezzeddine R, Walters I and Cheng AL: Brivanib versus sorafenib as first-line therapy in patients with unresectable, advanced hepatocellular carcinoma: results from the randomized phase III BRISK-FL study. J Clin Oncol 31: 3517-3524, 2013.

7 Cainap C, Qin S, Huang WT, Chung IJ, Pan H, Cheng Y, Kudo M, Kang YK, Chen PJ, Toh HC, Gorbunova V, Eskens FA, Qian J, McKee MD, Ricker JL, Carlson DM and El-Nowiem S: Linifanib versus sorafenib in patients with advanced hepatocellular carcinoma: results of a randomized phase III trial. J Clin Oncol 33: 172-179, 2015.

8 Zhu AX, Rosmorduc O, Evans TR, Ross PJ, Santoro A, Carrilho FJ, Bruix J, Qin S, Thuluvath PJ, Llovet JM, Leberre MA, Jensen M, Meinhardt G and Kang YK: SEARCH: a phase III, randomized, double-blind, placebo-controlled trial of sorafenib plus erlotinib in patients with advanced hepatocellular carcinoma. J Clin Oncol 33: 559-566, 2015.

9 Sangro B, Gomez-Martin C and de la Mata M, Inarrairaegui M, Garralda E, Barrera P, Riezu-Boj JI, Larrea E, Alfaro C, Sarobe P, Lasarte JJ, Perez-Gracia JL, Melero I and Prieto J: A clinical trial of CTLA-4 blockade with tremelimumab in patients with hepatocellular carcinoma and chronic hepatitis C. J Hepatol 59: 81-88, 2013

10 Sangro B, Melero I, Yau TC, Hsu C, Kudo M, Crocenzi TS, Kim T-Y, Choo S, Trojan J, Meyer T, Kang Y-K, Anderson J, Dela Cruz CM, Lang L, Neely J and El-Khoueiry AB: Safety and antitumor activity of nivolumab (nivo) in patients (pts) with advanced hepatocellular carcinoma (HCC): Interim analysis of dose-expansion cohorts from the phase 1/2 CheckMate-040 study. ASCO Meeting Abstracts 34: 4078, 2016.

11 Bruix J, Merle P, Granito A, Huang Y-H, Bodoky G, Yokosuka O, Rosmorduc O, Breder V, Gerolami R, Masi G, Ross Paul J, Qin S, Song T, Bronowicki J-P, Ollivier-Hourmand I, Kudo M, LeBerre M-A, Baumhauer A, Meinhardt G and Han G: LBA-03 Efficacy and safety of regorafenib versus placebo in patients with hepatocellular carcinoma (HCC) progressing on sorafenib: results of the international, randomized phase 3 RESORCE trial. Ann Oncol 27: ii140-ii141, 2016.

12 Nakano M, Tanaka M, Kuromatsu R, Nagamatsu H, Sakata K, Matsugaki S, Kajiwara M, Fukuizumi K, Tajiri N, Matsukuma N, Sakai T, Ono N, Yano Y, Koga H, Kurogi J, Takata A, Sumie S, Satani M, Yamada S, Niizeki T, Aino H, Iwamoto H, Torimura $\mathrm{T}$ and Sata M: Efficacy, safety, and survival factors for sorafenib treatment in Japanese patients with advanced hepatocellular carcinoma. Oncology 84: 108-114, 2013.

13 Shingina A, Hashim AM, Haque M, Suen M, Yoshida EM, Gill S, Donnellan F and Weiss AA: In a 'real-world', clinic-based community setting, sorafenib dose of $400 \mathrm{mg}$ /day is as effective as standard dose of $800 \mathrm{mg} /$ day in patients with advanced hepatocellular carcimona, with better tolerance and similar survival. Can J Gastroenterol 27: 393-396, 2013.

14 Kudo M, Lencioni R, Marrero JA, Venook AP, Bronowicki JP, Chen XP, Dagher L, Furuse J, Geschwind JF, Ladron de Guevara L, Papandreou C, Sanyal AJ, Takayama T, Yoon SK, Nakajima $\mathrm{K}$, Lehr R, Heldner S and Ye SL: Regional differences in sorafenib-treated patients with hepatocellular carcinoma: GIDEON observational study. Liver Int 36: 1196-1205, 2016.
15 National Health Insurance Administration, Ministry of Health and Welfare, Executive Yuan: Universal Health Coverage in Taiwan. May 2012. Available from: http://www.nhi.gov.tw/ Resource/webdata/21717_1_20120808UniversalHealthCoverage. pdf.

16 Chiang CJ, Lo WC, Yang YW, You SL, Chen CJ and Lai MS: Incidence and survival of adult cancer patients in Taiwan, 20022012. J Formos Med Assoc 115: 1076-1088, 2016.

17 Ye SL, Chen X, Yang J, Bie P, Zhang S, Liu F, Liu L, Zhou J, Dou K, Hao C, Shao G, Xia Q, Chen Y, Yang J, Deng X, Liu Y, Yuan Y, Fu Z, Nakajima K, Yip CS and Lu Z: Safety and efficacy of sorafenib therapy in patients with hepatocellular carcinoma: final outcome from the Chinese patient subset of the GIDEON study. Oncotarget 7: 6639-6648, 2016.

18 Kim DY, Kim HJ, Han KH, Han SY, Heo J, Woo HY, Um SH, Kim YH, Kweon YO, Lim HY, Yoon JH, Lee WS, Lee BS, Lee HC, Ryoo BY and Yoon SK: Real-life experience of sorafenib treatment for hepatocellular carcinoma in Korea: From GIDEON data. Cancer Res Treat 48: 1243-1252, 2016.

19 Lim CS, Lee YG, Koh Y and Heo DS: International comparison of the factors influencing reimbursement of targeted anticancer drugs. BMC Health Serv Res 14: 595, 2014.

20 Sacco R, Bargellini I, Ginanni B, Bertini M, Faggioni L, Federici G, Romano A, Bertoni M, Metrangolo S, Altomare E, Parisi G, Tumino E, Scaramuzzino A, Bresci G and Bartolozzi $\mathrm{C}$ : Long-term results of sorafenib in advanced-stage hepatocellular carcinoma: What can we learn from routine clinical practice? Expert Rev Anticancer Ther 12: 869-875, 2012.

21 Shao YY, Lu LC, Lin ZZ, Hsu C, Shen YC, Hsu CH and Cheng AL: Prognosis of advanced hepatocellular carcinoma patients enrolled in clinical trials can be classified by current staging systems. Br J Cancer 107: 1672-1677, 2012.

22 Shau WY, Shao YY, Yeh YC, Lin ZZ, Kuo R, Hsu CH, Hsu C, Cheng AL and Lai MS: Diabetes mellitus is associated with increased mortality in patients receiving curative therapy for hepatocellular carcinoma. Oncologist 17: 856-862, 2012.

23 Shao YY, Wu CH, Lu LC, Chan SY, Ma YY, Yen FC, Hsu CH and Cheng AL: Prognosis of patients with advanced hepatocellular carcinoma who failed first-line systemic therapy. J Hepatol 60: 313-318, 2014.

24 Lin TH, Shao YY, Chan SY, Huang CY, Hsu CH and Cheng AL: High serum transforming growth factor-betal levels predict outcome in hepatocellular carcinoma patients treated with sorafenib. Clin Cancer Res 21: 3678-3684, 2015.

25 Shao YY, Shau WY, Chan SY, Lu LC, Hsu CH and Cheng AL: Treatment efficacy differences of sorafenib for advanced hepatocellular carcinoma: a meta-analysis of randomized clinical trials. Oncology 88: 345-352, 2015. 